\title{
A-BIM: A New Challenge for Old Paradigms
}

\author{
Leonardo Prazeres Veloso de Souza ${ }^{1}$, Angélica Paiva Ponzio ${ }^{2}$, \\ Underléa Miotto Bruscato ${ }^{3}$, Airton Cattani ${ }^{4}$ \\ 1,2 PROPAR/UFRGS ${ }^{3}$ PGDesign/UFRGS ${ }^{4}$ PROPAR/UFRGS, PGDesign/UFRGS \\ 1,2\{leoprazeres13|angelica.ponzio\}@gmail.com \\ ${ }^{3,4}\{$ underlea.bruscato|aacc\}@ufrgs.br
}

\begin{abstract}
This paper is the result of a pedagogic proposal applied to undergraduate students of architecture in order to present new digital design tools and methods. This study aims to connect procedural contents to different design strategies enrolled by students with special focus on complex geometries. The objective was to offer the necessary assistance to an appropriated design development, by reducing the habitual mishaps related to the lack of technical skills with digital tools for both the design reasoning and the subsequent graphic representation of proposals. As an answer, a new design approach called A-BIM (Algorithmic-based Building Information Modeling) was introduced to students, which integrates BIM platforms with algorithmic modelling software allowing, in this way, some formal flexibility allied to an adequate graphic documentation.
\end{abstract}

Keywords: $A$-BIM, algorithmic design, BIM technology, parametric software

The teaching and learning processes of architectural design undertaken by educational institutions is extremely diverse. Even though the usual tripod - theory, practice and instrumentation - is present in most schools, there are divergences of approaches between them. Among the many design tools available in the instrumental context, the digital ones are those undertaking a faster pace, modifying, according to Kolarevic (2003), architectural practices in ways that would be difficult to imagine decades ago.

Graphic representation is the means by which architects and designers engage in a reflexive conversation about a given design problem(SCHÖN, 1983; DO e GROSS, 2001; LAWSON, 2011). In other words, it is the environment where ideas flow from the mental world to the real world, allowing for a greater clarity of reasoning, but also a certain degree of am-
biguity(OXMAN, 2002), which are necessary characteristics for new ideas to emerge from the analysis and iterations made with these drawings. Therefore, graphic representation occupies a central position in the creative process of architects and designers.

According to Mitchell(2008), architects often create implicit design worlds through their choice of drawing instruments and representational media. These design worlds, in turn, can be elaborated in different ways using various techniques and methods. In architecture, it can be seen that the most common techniques currently used are physical models, manual/analog drawings (sketches) and computational drawings and models.

Also according to Mitchell, each media has its axioms, that is, intrinsic rules that are relative to each technique of graphic representation, those that are 
inherent to it. For example, a design world created by a drawing made with pencil and paper allows a fluid trait and quick ideation, however, the representation is made one view at a time and in a two-dimensional manner. On the other hand, when using representation software and digital graphic modeling, architects are able to obtain the complete volume of the architectural object, allowing multiple views simultaneously. On the other hand, it can be limited by the scope of the programming methods of each software, thus hindering creativity. It is necessary, therefore, to know the axioms and limitations imposed by each representational media used.

From the emergence of Computer Aided Design (CAD) technology to its popularization between architects, engineers and designers, there have been transformations not only in technology but also in society's life, making design practice increasingly intertwined with computational technologies as can be seeing in Weisberg (2008). At the end of the first decade of 2000 in Brazil, while Orciuoli (2010) claimed that some architectural schools still looked suspiciously upon the digital, Barison and Santos (2010) emphasized the appropriate moment to introduce parametric software such as the BIM platform (Building Information Modeling) in the undergraduate architectural curriculum.

Nevertheless, there are scholars that focus on the challenge of formulating an appropriated digital design framework in order to bring even more advanced technologies such as algorithmic and parametric visual programming associated with rapid prototype technology, as seen in Sass and Oxman (2006) and Sedrez and Celani (2014). According to Romcy (2017), in Brazil this paradigm shift is occurring at a slow pace, and only a few architecture schools have recently adopted programming disciplines in their curriculum.

In this scenario, Sofia Feist (2016) claims that the A-BIM technology - a combination of algorithmic processes with the BIM methodology, can offer many benefits to the architectural design process. According to Ruschel (2014) and Wahbeh (2017) connecting the formal freedom of algorithmic design to the standardized control of BIM, could be a best combination for a creative flexible information model.

Corroborating with the advance of this new paradigm to architectural design education, this paper presents a case study developed as part of a Master's Architectural degree thesis presented in 2018. The main objective is to implement and analyze the use of an integrated A-BIM (Algorithmic Based Building Information Modeling) technology applied in an intermediate undergraduate design studio at a Brazilian Architecture School.

\section{METHODOLOGY}

Since 2017, the curriculum of the Architecture School of the Federal University of Rio Grande do Sul (UFRGS) has been undergoing a transitional period from a CAD to a BIM platform (the BIM platform Archicad is taught in the 3rd semester in the discipline of RGII). In order to fully understand the school's curriculum, this research started in the first semester of 2017. By then, an analysis was carried out in two disciplines, one instrumental and the other a design studio, aiming to understand their dynamics and pedagogical approaches. This facilitated the study of possible focused interventions to introduce algorithmic modeling software and its interlacing with the BIM platform.

To participate in this study, in 2017 two undergraduate disciplines of the fourth semester were strategically chosen. They were Graphic Representation III (RGIII) and Architectural Design II (P2). The former is responsible for developing in the students both manual and digital skills while encouraging their ability to analyze architectural design; RGIII also has in its pedagogical history the tradition of teaching hybrid graphic representations, corresponding to part of the student's computational instrumentation and graphical representation with analogic, digital and prototyping resources. The latter, $\mathrm{P} 2$, besides being responsible for the design practice, also has the capability of integrating knowledge acquired during the fourth period; a fertile ground where these experiences can be directly applied. 
Figure 1

Explicit algorithmic reasoning
During the actual experiment, in the second semester of 2017, the RGIII discipline (one class, 45 students and 3 professors) was specifically dedicated to enhancing the students with the instrumental ground needed for a potential paradigm shift in their architectural design projects. The P2 design studio $C$ (one professor and fourteen students), on the other hand, was the design class selected because of its pedagogical approach, which employs initial abstract conceptual explorations and their metaphorical symbols to compose the formal proposals of the student's architectural designs.

The pedagogical interventions proposed in both disciplines presented the students with exercises that enabled them to explore the interface between a process previously unknown to students - the creation of algorithms in Grasshopper software and manipulation of the resulting objects in a BIM environment using Archicad software. Thus, while the RGIII discipline focused almost exclusively on the instrumentalization of students with the Grasshopper algorithmic and parametric platform, P2 encouraged them to use that platform in the development of design proposals in order to obtain greater freedom in formal and conceptual exploration.

\section{RGIII}

In RGIII, the exercise proposed was to model a building with low geometric complexity, but totally parameterized. In that way, it would either be possible to control the level of complexity presented, while at the same time benefiting of parametric reasoning in a context closer to reality (Figure 1). The parameterized model developed was a small shelter using woodframe constructive technique, in a way that the knowledge acquired could be used in the P2C class.

The exercise started by describing a profile of parameterized edges with their dimensions regulated by standards inherent to the constructive and modular system in woodframe. This profile served as a generator of the initial building volume, this way it was possible to construct, from the beginning, a reasoning that respected the modulation of the proposed constructive system while having the formal flexibility both in the initial profile and in its longitudinal dimensions, which are described later.

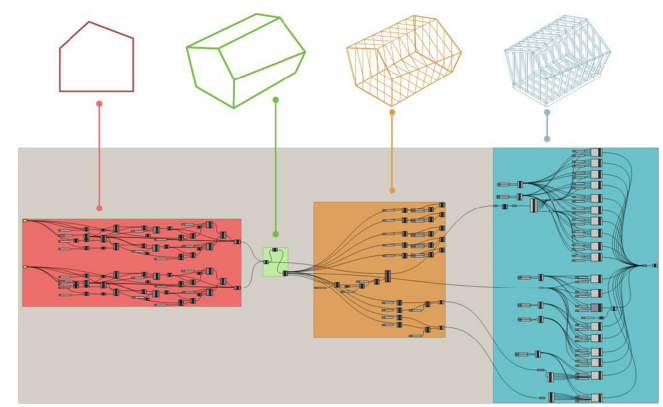

In the second stage of the exercise, a loft operation with modular distance was performed between two profiles, which had the same algorithmic description, but with different parameter values, generating in this way a volumetry that connected profiles with varied morphologies and generating non co-planar surfaces. Then with the defined volumetry, transverse and longitudinal sections were drawn with regular spacing according to a modular woodframe system. In this specific case the building volume was sectioned every $60 \mathrm{~cm}$, in order to obtain guidelines for the structural parts. From these lines, structural profiles with dimensions described algorithmically according to the position, size of the span or structural function were incorporated, following the woodframe construction guidelines indicated by Thallon (2008)and Ching(2016).

These structural profiles were incorporated into the guidelines using A-BIM technology. In this study, the "Grasshopper Archicad Live Connection" (GALC) plug-in was used to integrate algorithmic software into the BIM platform, allowing the insertion of native constructive information of Archicad into the abstract geometries generated by Grasshopper. In parallel, these geometries were transmitted in real time to Archicad, so it was possible to obtain graphical technical representations such as plans, sections and elevations, or even more complex details. 
At the end of the process, it was possible to demonstrate to the students the resilience of the proposal presented when determining dimensional changes in both the generative profiles and the longitudinal dimensions of the volume as a whole. It was also possible to realize that the structures described algorithmically were able to correct themselves to the new positions and dimensions automatically (Figures 2, 3 and 4) at the same time as they were transmitting the new volume generated for the BIM platform.
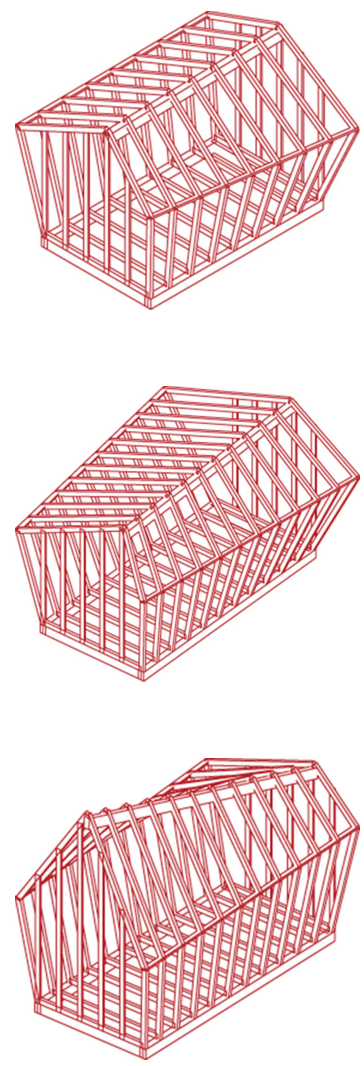

Furthermore, video-classes were made available to the students on the Internet containing more complex operations than those performed in class, complementing and stimulating the learning of parametric tools in different contexts applied to architecture.

\section{P2C}

The work developed in $\mathrm{P} 2 \mathrm{C}$ consisted of the design of a small building employing woodframe construction technology. The theme of the project was a design hotel located outside the urban perimeter of the city of Porto Alegre-RS with a strong tourist appeal and fully integrated with nature. One of the main premises of the discipline was to connect conceptual ideas to practical solutions using design thinking techniques, proving to be a propitious discipline for formal exploration with a strong focus on conceptual design.

According to Laura Garcia (2012), design thinking uses inductive logic, admitting that it is impossible to attest to a new concept or idea in advance without first observing the development of future events. Thus, design thinking differs from the conventional approach used to solve problems because it helps in the exploration of new knowledge.

During the design concept and formal studies, the algorithmic platform was presented as an alternative media to the class. In this sense, specific interventions were suggested at key moments of the design process, with the aim of providing a possible digital focus during the students' creative thinking.

Added to the project discipline schedule were lectures on generative systems and parametric architectures applied to architecture, landscaping and urban planning projects. These classes served to instill students' curiosity about the suggested design strategies as well as provide a theoretical background to assist them throughout the creative design process developed during the semester.

One of the stages of the discipline provided for the creation of a graphic symbol that would synthesize the concept of the hotel. This synthesisform could serve as an icon, a mark or a symbol of
Figure 2

Initial Loft Structure

Figure 3

Loft Structure 02.

Changes in profiles and volume dimensions

Figure 4 Loft Structure 03. Changes in profiles and volume dimensions 
Figure 5

Modeling Process T3 the project and had the purpose of translating into simplified graphic elements the concepts expressed hitherto mostly in textual character, articulating the concept to form.

Starting from this synthesis-form, theoretical and practical classes were undertaken before the launch of the architectural concept of the building, presenting concepts related to shape grammar. Thus the students could become familiar with principles such as atomic elements, systems and vocabulary of forms. Next, an exercise was suggested to use these concepts in practice. It was suggested that to the students to deconstruct their synthesis-forms into atomic elements, and to recombine them using formal operations derived from shape grammar, such as symmetry, rotation, translation and deformation, among others.

Students had the freedom to perform these operations in an analog or digital environment. In order to perform the exercise in a digital environment, algorithms were produced in the Grasshopper software in a way that the students could manipulate the atomic forms or sets of elements and generate combinations from symmetric or recursive formal operations, both two-dimensional and three-dimensional.

The main purpose of the exercise was to introduce a playful process of formal exploration into the digital environment that generated a wide variety of options, while keeping the synthesis-form elaborated by the students and maintaining the coherence with concept defined in previous stages. This way, it was possible to observe a great variety of formal options on the same architectural concept (SOUZA, 2018).

Among the 14 students enrolled, 4 of them choose to keep on exploring the algorithmic environment according to their project's formal and technical complexities. These students, for classification purposes, were designated as T3 while the others as T1. In order to deal with the formal complexity of the architectural concepts developed, the modeling methodology of RGIII was used and improved (figure 5). This methodology was separated into 5 steps, of which, 4 modeling and 1 detailing.

1 - Surface Modeling (Rhinoceros 5 + Grasshopper);

2 - Guidelines Description (Grasshopper);

3 - Structural profiles Description (integrated Archicad);

4 - Modeling of the closing surfaces (integrated Archicad);

5 - Detailing and final graphic representation (Archidad and/or other software).

By analyzing figure 5, only a small part of the design process represented the core of formal exploration. Thus, the students were able to describe complex shapes using few surfaces or primary lines with the rest of the process adapting to these in an algorithmic way.

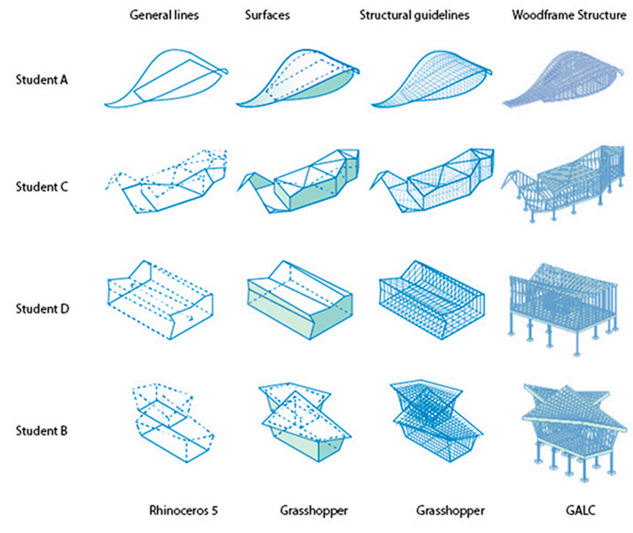

\section{RESULTS}

At the end of the semester, different types of data were collected and analyzed in an attempt to better understand the design process and to verify if there was a positive contribution by the interventions made in the targeted by the students, the data collected consisted of photographic records, class notes, student testimonials, and semi-structured interviews via Google Forms. 


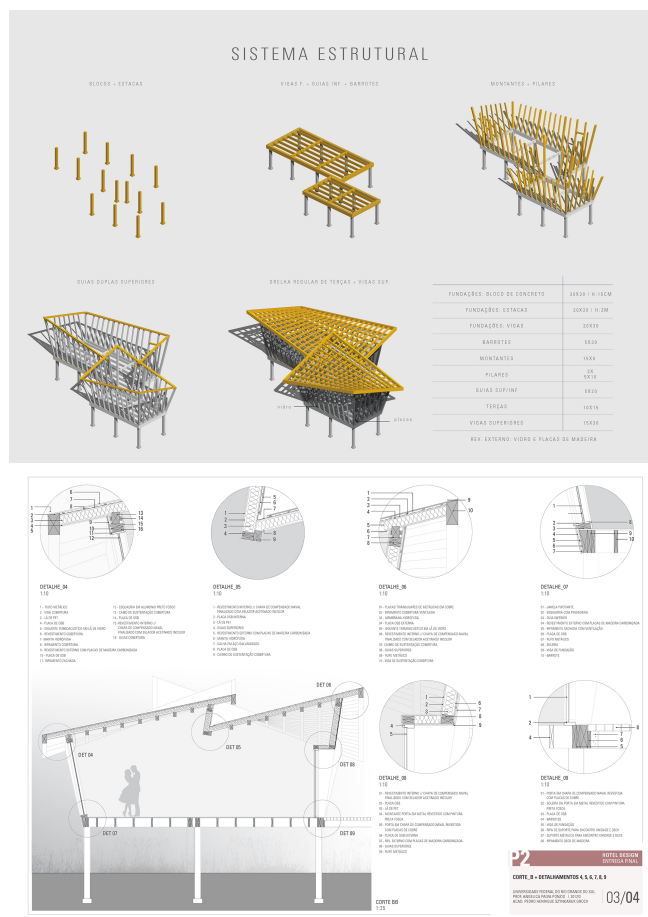

By presenting another possibility of project investigation, the results demonstrated that the T3 student group could successfully visualize the geometric relations during form generation and simultaneously obtain the architectural documentation needed for technical purposes (figure 6).

Corroborating with the previous findings, it was possible to observe the topological complexity achieved by T3 students revealing a clear difference between forms developed by students T1 and T3. In the T1 category, mostly orthogonal prismatic surfaces were employed, developing simple formal operations such as addition, subtraction or extrusion. On the other hand, T3 students chose to work with non-coplanar surfaces, tessellations, and "lofts" between different profiles, generating more complex forms than those from T1 group. Even though its differences, all students were able to reach satisfactory levels in their designs.
This experiment also indicated problems to be further analyzed and solved in future proposals, starting with the overall difficulty presented by the lack of intuitiveness of Grasshopper. Comparatively, this software takes a completely divergent approach from others most commonly used by students like SketchUp, Autocad, Archicad or Revit. In order to overcome this difficulty, constant monitoring was necessary as well as the production of complementary pedagogic material in order to enable T3 students to successfully finish their proposals (SOUZA 2018).

Another difficulty observed during the research was the presence of some issues in the data transmission between Grasshopper and Archicad using the GALC plug-in, amongst those, the following:

- Alignment Bugs: Alignment errors between profile and tabbed lines often occurred with divergence in the transmission of data from the position of some parts of the woodframe structure in Grasshopper to Archicad.

- Problems in the formation of complex surfaces with the "Shell Ruled" tool: this tool proved to be too limited to generate surfaces that did not have parallelism on at least one axis which proved to be insufficient for some proposals. To overcome this problem it was necessary to use several layers of "morph" surfaces.

- Interruption of the model update: The update generated in Grasshopper and transmitted to Archicad was interrupted frequently, making it was necessary to delete the model and then restart the connection.

- High hardware consumption: High consumption of hardware was noted, even in powerful computers, so this approach had a limited scope due to financial resources, making it less democratic.

- Unidirectional Workflow: The T3 category students were surprised by the unidirectional workflow of the plug-in. They would rather work with a bidirectional flow, which could
Figure 6 Modeling Process T3 
Figure 7

Diagrams with the different approaches undertaken by T3 students enable them to update the algorithm through the direct manipulation of geometry components.

However, in spite of the problems faced, the proposed methodology proved to be flexible allowing different levels of software knowledge during the design process as we can see in figure 7. This way, even students with little instrumental skills in one of the programs used in this methodology were able to complete their creative processes and their respective graphic representations at the end of the semester, allowing them to overcome typical software limitations.

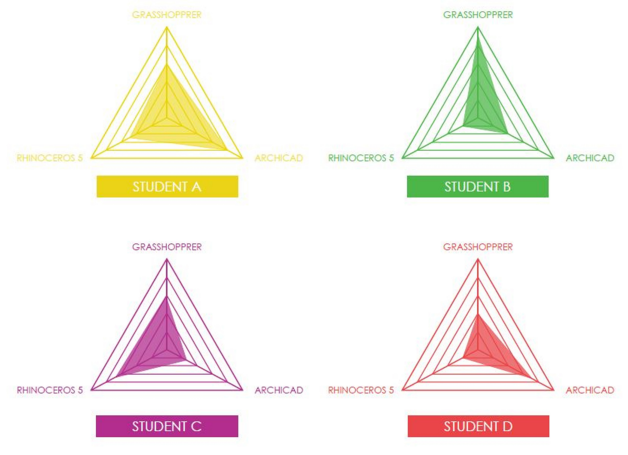

\section{DISCUSSION}

The aim of this research was to contribute to the enlargement of students' design capabilities at a conceptual and formal level while employing a constructive system based on strict constraints such as woodframe. By combining experiences of creating and manipulating forms with algorithms to construction techniques and that of representation and documentation required in design disciplines, we seek to encourage the student's exploration of new design processes.

In order to do that, this research sought to delineate a divergent design process, by offering thru A-BIM a more continuous design workflow. This way, by minimizing software migration during the design process of T3 students, this research allowed the development of complex forms even using a restrictive constructive system that has rigid rules such as woodframe.

Also, by analyzing the final results developed by T3 students, it was possible to verify the cognitive and procedural benefits, as well as the methodological difficulties, and limitations inherent from the use of these technologies in innovative teaching methodologies. In this way, the study claims to contribute to future experiments, mapping new research possibilities and pointing out technical issues to be solved in the implementation of these design techniques with students.

In conclusion, it was possible to verify that the integration between the BIM platform and algorith$\mathrm{mic}$ /parametric software constitutes a favorable environment to stimulate creative reasoning, as well as to facilitate the graphic representation of complex forms conceived in the parametric digital environment, as long as a suitable base is provided.

\section{REFERENCES}

BARISON, MB and SANTOS, ET 2000 'REVIEW AND ANALYSIS OF CURRENT STRATEGIES FOR PLANNING A BIM.', NTERNATIONAL CONFERENCE ON APLPLICATIONS OF IT IN THE AEC INDUSTRY\& ACCELERATING BIM RESEARCH WORKSHOP, Cairo, Egypt, pp. 1-11

CHING, FDK 2016, Técnicas de Construção Ilustradas., Bookman, Porto Alegre

DO, EY and GROSS, MD 2001, 'Thinking with Diagrams in Architectural Design.', Artificial Intelligence Review, 15(1/2), p. 135-149

FEIST, STV 2016, A-BIM区: Algorithmic-Based Building Information Modelling., Técnico de Lisboa, Lisbon

GARCIA, LM 2012, 'nderstanding Design Thinking, Exploration and Exploitation., IDBM Papers, 2, p. 151-161

LAWSON, B 2011, Como Arquitetos e Designers Pensam, Oficina de TExtos, Sao Paulo

LIU, YT and LIM, CK 2006, 'New Tectonics: A Preliminary Framework Involving Classic and Digital Thinking., Design Studies, 27, p. 267-307

MITCHEL, W 2008, A Lógica Da Arquitetura. Projeto, Computação e Cognição., UNICAMP, Campinas

ORCIUOLI, A 2010, 'Quebrando Tabus.', Vitruvius - Drops, 030-010, p. 1 
OXMAN, R 2002, 'The Thinking Eye: Visual Re-Cognition in Design Emergence.', Design Studies, 23, p. 135-164

ROMCY, NMS 2017, Abordagem Paramétrica e Ensino de Projeto - Proposição de Diretrizes Metodológicas, Considerando Estratégias Curriculares e o Atelier de Projeto, Ph.D. Thesis, Federal University of Rio Grande do Sul

RUSCHEL, RC 2014 'To BIM or Not to BIM区?', Encontro da Associação Nacional de Pesquisa e Pós囚Graduação em Arquitetura e Urbanismo, Sao Paulo, p. 1

SASS, L and OXMAN, R 2006, 'Materializing Design: The Implications of Rapid Prototyping in Digital Design., Design Studies, 27, p. 325-155

SEDREZ, M and CELANI, G 2014, 'Ensino de Projeto Arquitetônico Com a Inclusão de Novas Tecnologias: Uma Abordagem Pedagógica Contemporânea.', Pós, 21(35), p. 78-97

SOUZA, LPV 2018, Os caminhos do projeto na plataforma digital: uma investigação pedagógica do processo projetual no ambiente paramétrico, Master's Thesis, Federal University of Rio Grande do Sul

THALLON, R 2008, Graphic Guide to Frame Construction. Tauton Press, Newtown

WEISBERG, DE 2008, The Engineering Design Revolution - The People, Companies and Computer Systems that Changed Forever the Practice of Engineering, David E. Weisberg, Englewood 